\title{
LOS ADELANTOS DE LA CIENCIA Y LA PERMEABILIDAD DEL DERECHO: REFLEXIONES EN TORNO A LA "REPRODUCCION HUMANA ASISTIDA"
}

Beatriz Boza Dibos*

¡Eureka! exclamó Arquímedes cuando descubrió el método para determinar la pureza del oro. ¡Eureka! dijo Newton al establecer el principio de la gravedad. ¡Eureka! exclamaron Einstein, Pasteur y Von Braun, expresando de esa manera su satisfacción por haber logrado un descubrimiento científico. Desde épocas remotas los científicos han sorprendido al mundo entero con sus descubrimientos, contribuyendo de una u otra forma al desarrollo y progreso de nuestra civilización. La medicina, en tanto busca proteger la salud de los seres humanos, ocupa, sin duda, un lugar privilegiado en esta evolución.

¿Quién hubiera jamás imaginado la posibilidad de fertilizar un óvulo humano en probeta! iHoy la placenta artificial, la "procreación por correo" y el embarazo masculino han dejado de ser fantasía! "Desde 1944 en que los científicos por prim era vez observaron por el microscopio la unión del esperma humano con el óvulo, la Fisiología, la Genética, la Embriología y Obstetricia se han desarrollado de manera vertiginosa. Hoy en día los médicos pueden estimular el proceso de ovulación, extraer el óvulo, fertilizarlo fuera del cuerpo

$\left(^{*} \quad\right.$ Las reflexiones aquí vertidas se inspiran en el Seminario "The New Reproductive Technologies and the Law" dictado por el profesor Dr. Jay Katz en la Facultad de Derecho de la Universidad de Yale, EE.UU. en el año académico 1987/1988 y están dedicadas al Dr. Katz, ejemplo de vida, guía y amigo, con estima y admiración. Un agradecimiento especial merece la doctora Anne C. Reichman, Asesora de la Comisión de Bioética del Estado de Nueva Jersey, EE.UU. por sus invalorables aportes en nuestros constantes intercambios de ideas. 
humano, e implantar el embrión en el útero de quien donó el óvulo o de una tercera persona. Los médicos pueden observar directamente al feto a lo largo del embarazo, pueden diagnosticar y tratar sus enfermedades en el útero; $e$ incluso pueden removerlo temporalmente para su curación". (1)

Estos adelantos que se han venido en denominar lo que se conoce hoy bajo el término "Reproducción Humana Asistida", permiten separar los aspectos genético, gestacional y social de la procreación (2) recombinándolos de las más diversas maneras (3). Así como la "píldora" contribuyó a disociar el vínculo sexualidad-procreación en el sentido de impedir la concepción, las nuevas técnicas de "Reproducción Humana Asistida" permiten engendrar un bebé sin necesidad de coito sexual. (4)

La supervivencia de nuestra especie sobre la faz de la tierra está íntimamente ligada a la procreación de nuevas generaciones. En este sentido la reproducción de la especie humana es vital a todo orden social. No sólo satisface la necesidad socio-cultural de perpetuar la especie sino también necesidades biológicas y psicológicas del individuo: su instinto natural de subsistencia.

(1) ROBERTSON, John. Procreative Liberty and the Control of Conception, Pregnancy and Childbirth. 69 Virginia L. Rev., 1983. p. 407 (Traducción libre).

(2) Los padres genéticos son quienes procuran los gametos, la madre gestacial es quien gesta a la criatura desde la concepción hasta su alumbramiento, y quienes crian y educan al niño son los padres sociales.

(3) ROBERTSON, Op.Cit. p. 420 y s. explica que hasta seis personas distintas pueden participar en la procreación, esto sin contar al personal médico. Los seis involucrados serían: la mujer que provee el óvulo, la mujer que gesta, el varón que provee el esperma, la pareja que cría al niño y el esposo de la mujer gestante.

(4) KASS, Leon. Making Babies Revisited.54. Public Interest, 1979, p. 48, nota no. 10, atribuye a la pildora la formula "sex without babies", mientras que las nuevas técnicas permiten tener "babies without sex". 
Los adelantos de la ciencia en materia de procreación humana despliegan un abanico de posibilidades, inquietudes y situaciones nunca antes imaginados, que nos confrontan con cuestiones éticas legales, sociales y morales de las que difícilmente nos podremos deshacer.

La ciencia nos ha aventurado hacia nuevas áreas del saber. La tarea de quienes nos desenvolvemos en el campo de las Humanidades, consiste en estudiar con detenimiento cada uno de estos adelantos, sus bondades e implicancias, los riesgos a que nos exponen y el precio que la sociedad en su conjunto tendrá que pagar por ello. Debemos proyectarnos al futuro a fin de establecer cómo y cuáles de nuestros valores podrían resultar afectados. Teólogos, juristas, filósofos, sociólogos y antropólogos deben contribuir a informar las decisiones del legislador y del gobernante. Tal vez hubiésemos evitado Hiroshima y Nagasaki si Truman hubiese contado con estudios al respecto. Por lo menos habría pensado dos veces antes de ordenar la detonación de la bomba atómica. No obstante, grandes errores también contribuyen a nuestra evolución. Ahora, como en ese entonces, la tecnología está al alcance de nuestras manos. Antes de decidir qué hacer con ella, debemos reflexionar con detenimiento el destino que nos depara. Asumiendo este imperativo nos avocamos al estudio de tan controvertido tema.

\section{Las nuevas tecnologias}

La Reproducción Humana Asistida engloba diversos procedimientos y tecnologías, entre los que se destacan la inseminación artificial, fertilización in vitro, transferencia de embriones, cesión de vientre, $\mathrm{y}$ la preservación de gametos y embriones.

Antes de explicar en qué consiste cada uno de estos avances de la ciencia moderna es conveniente definir qué se entiende por fertilización y cuándo estamos ante una "fertilización natural". La fertilización es el proceso por el cual el óvulo femenino es fecundado por el espermatozoide masculino, fusionándose así el pronuclei masculino y femenino en una nueva unidad, con información genética propia. 
Este proceso se desarrolla durante varias horas (5). La relación sexual entre dos adultos fecundos da lugar a una "fertilización natural".

Ahora bien, en el caso de la inseminación artificial (en adelante "IA") se toma del esperma masculino el semen necesario para hacerlo llegar al óvulo femenino, facilitando así la fecundación en el vientre materno. Es artificial en tanto la introducción del semen en el útero obedece a causas distintas a la "natural". El semen utilizado puede ser del cónyuge - en cuyo caso estamos ante la inseminación artificial homóloga (IAH) - o de un tercero. Este último tipo se denomina inseminación artificial heteróloga o por donación (en adelante IAD).

La fertilización in vitro (FIV), como su nombre lo indica, supone que el proceso de fertilización ocurre en probeta. El procedimiento es bastante complejo, pero en términos generales supone (6): a) Superovulación (7) (las posibilidades de embarazo son escasas si sólo se transfiere un embrión al útero, de ahí que sea necesario obtener varios óvulos); b) Intervención quirúrgica para remover los óvulos maduros (8); c) Fertilización in vitro con semen previamente analizado y preparado para la inseminación; d) Incubación por algunos días

(5) GROBSTEIN, Clifford. The Early Development of the Human Embryo, en 10. J. Med. \& Phil., 1985, p. 214.

(6) Ontario Law Reform Commission: Report on Human Artificial Reproduction and Related Matters, Ministry of the Attorney General 1985 (en adelante Ontario Report); Department of Health \& Social Security: Report of the Committee of Inquiry into Human Fertilization and Embryology, Her Majesty's Stationary Office Cmnd. 9314, Londres 1984, p. 29: (en adelante Warnock Report); ROBERTSON, John: Embryos, Families and Procreative Liberty: The Legal Structure of the New Reproduction, 59 So. California L.R., 1986, p. 947 y ss; Aaron Lifechez en Smith v. Harting, 566 F. Supp. 157, 1983, nota nr. 4.

(7) El Dr. Alan Trounson de Melbourn, Australia, ha desarrollado la técnica de superovulación comúnmente utilizada en FIV, en virtud de la cual se estimulan artificialmente los ovarios. (ROBERTSON, op.cit., p. 948).

(8) Esta técnica se conoce como "laparoscopy" y se practica bajo anestesia 
a fin de constatar su normal desarrollo; y e) Implantación de varios embriones en el útero femenino.

Este último paso constituye una modalidad de la transferencia de embriones (en adelante TE). La otra forma de transferencia de embriones se conoce como "lavage" y supone la fertilización in vitro del óvulo mediante inseminación artificial y luego de tres o cuatro dias, justo antes de la implantación, se remueve el óvulo fertilizado para transferirlo al útero de otra mujer, cuyo ciclo menstrual ha sido sincronizado con el del donante (9).

A su turno, lo que se ha venido en denominar "madre sustituta", - "cesion o alquiler de vientre", no es propiamente una forma de concepción artificial sino la gestación de un embrión en el vientre de otra persona. La madre sustituta gesta a la criatura desde la concepción hasta el alumbramiento. Podríamos decir que funge en última instancia a manera de incubadora (10).

Otro de los adelantos en este campo es la posibilidad de preservar semen y óvulos fecundados mediante el proceso de "cyropreservation" o congelación. Si bien la ciencia no ha logrado detener el transcurso del tiempo, por ejemplo congelando a una persona, es posible congelar embriones humanos para su uso futuro. En junio de 1986 se registró en Los Angeles, USA, el primer nacimiento de una persona humana cuyo embrión habría sido sometido a este tratamiento (11).

Las posibilidades que brinda la ciencia son infinitas. Cada una

total. Otra técnica es la de "ultrasound-guided transvaginal aspiration" que si bien no requiere anestesia, es menos efectiva que la primera (ROBERTSON, op.cit., p. 948 y nota 26).

(9) Ontario Report vol. I, p. 28; Warnock Report punto ,7.1, p. 39. California Civil Code s. 7005.1 In Vitro Fertilization and Embryo Transfer (a) (2). ROBERTSON, op.cit., p. 950 y s.

(10) Ontario Report, vol. II, p. 218.

(11) ROBERTSON, op.cit., p. 450, nota nr. 34. 
de estas técnicas puede combinarse con las demás. Según Weaver y Escobar, existen ahora veinticuatro modos de poder traer hijos al mundo (12).

\section{Ventajas que procuran: el tratamiento de la infertilidad}

En 1985 la Comisión de Ontario encargada de evacuar un informe acerca de los nuevos adelantos en materia de procreación humana estimó que en Canadá más del 15 a $20 \%$ de las parejas eran infértiles (13). Aunque aún no se ha llegado a un consenso acerca de las causas y naturaleza de la infertilidad (14), podríamos decir que es la condición de una pareja que pese a repetidos intentos de concebir no está en aptitud de procrear, ya sea por oligospermia, azoospermia, baja densidad o ausencia de esperma, esterilidad a causa de una vasectomía, bloqueo o ausencia de las trompas de falopio, ausencia 0 útero defectuoso, ausencia de gametos, imposibilidad de quedar en cinta, endometrosis u otros (15).

Tradicionalmente algunos casos de esterilidad han sido tratados con hormonas, otros mediante intervenciones quirúrgicas y muchos sencillamente no tienen cura. Quienes, pese a ello, anhelaban tener una familia para realizarse y vincularse con el futuro, tenían que recurrir a la adopción.

La adopción no sólo daba respuesta a los casos de infertilidad

(12) WEAVER, David y ESCOBAR, Luis. Twenty-Four Ways to Have Children, 26 Am. J. Medical Genetics, 1987, Carta al editor, p. 737 y ss.

(13) Ontario, p. 10.

(14) ROBERTSON, John. Procreative Liberty and the Control of Conception, Pregnancy \& Childbirth, 69. Virginia. L. Rev., 1983, p. 430, nota nr. 67, sostiene que la fertilidad no es sólo una condición objetiva y cierta sino, en cierto modo, basada en factores sociales y económicos. KASS, Leon. The New Biology and the Old Morality, 26 Public Interest, 1972 , p. 20 , considera que la infertilidad es tanto una relación como una condición.

(15) Ontario Report. 
sino a todos aquellos casos de enfermedades genéticas hereditarias, tales como la hemofilia, anormalidades cromosomales, Tay-Sachs o Huntington. Además aquellos casos en que la mujer de factor Rh negativo está $\mathrm{Rh}$-isomunizada y el padre es Rh positivo, o aquellos matrimonios en que la mujer, por su edad, tiene escasas posibilidades de salir encinta. La necesidad de encontrar un alivio a estas situaciones motivó el adelanto de la ciencia que hoy conocemos como Reproducción Humana Asistida.

Las nuevas técnicas proporcionan un tratamiento eficaz para la gran mayoría de parejas infértiles, permiten que quienes temen transmitir malformaciones genéticas puedan tener hijos que están biológicamente relacionados por lo menos a uno de los padres, y otorgan a la pareja un mayor control sobre su actividad procreativa.

Sin embargo, los "beneficios" derivados de estos adelantos van más allá: permiten controlar las características del embrión (sexo, color de los ojos, contextura), manipular el material genético para satisfacer el gusto de sus progenitores, traer hijos genéticamente relacionados a uno sin tener que participar en su concepción, gestación y/o alumbramiento, hacen posible el "clonning" (16) y responden al pedido de los solteros, así como de las parejas homosexuales, de tener descendientes genéticamente vinculados a ellos. Para quienes a pesar de no haber podido encontrar una pareja con quien compartir su futuro deseen concebir, gestar y alumbrar un hijo, para quienes quieran experimentar la satisfacción de trasmitir su material genético $\sin$ tener que asumir las responsabilidades inherentes a la gestación o paternidad, para quienes, por cualquier otro motivo, quieran participar de una u otra forma en la procreación, la Reproducción Humana Asistida les permite realizar sus tan anhelados objetivos (17).

(16) El "clone" es un individuo genéticamente idéntico a su progenitor. Tiene un único progenitor. En 1952 el Instituto para la Investigación del Cáncer en Philadelphia produjo clones de sapos (TRIBE, Laurence: Technology Assessment and the Fourth Discontinuity: the limits of Instrumental Rationality, 46 Southern Cal. L.R. 1973, p. 617 y ss).

(17) Así también ROBERSTSON, op.cit., p. 424. 


\section{Regulación permisiva}

El abanico de posibilidades que ofrece la ciencia no se agota en esta enumeración; rebasa todas las previsiones que pudiésemos haber imaginado. ¿Significa esto que su uso debe ser ilimitado? ¿No deben, acaso, regularse bajo ciertos criterios e imponerse standars para la aplicación de estos métodos? Aun quienes propugnan la mayor liberación en esta materia reconocen la necesidad de su control.

\section{a) ¿Quién debe reglamentar?}

El abogar por la reglamentación no desconoce la importancia y autonomía que la procreación tiene en el seno familiar. Nada por el estilo. Como veremos más adelante al ocuparnos del llamado "derecho a procrear", la intervención estatal no es deseable ni posible en el caso de la "procreación natural". Dada la complejidad de este tema, pospondremos su estudio por un momento.

La pregunta inicial es quién debe tomar cartas en el asunto, ¿no son acaso las partes involucradas quienes mejor que nadie pueden velar por sus intereses? ¿Hasta qué punto podemos confiar en la profesión médica para que adopte las normas del caso? Dejar todo en manos de los científicos resulta riesgoso y cuestionable, no sólo porque operan de acuerdo a sus propios criterios, sino porque, además y sobre todo, no están preparados ni legitimados para tomar decisiones que afectan a la sociedad en su conjunto. Los colegios profesionales pueden $-\mathrm{y}$ debensancionar normas de conducta aplicables y controladas al interior del gremio. Es, por el contrario, tarea del legislador sentar las bases y principios que enmarquen la actividad de la sociedad (18). Dejar todo en manos de las partes involucradas impor-

(18) Ontario Report, Vol. I, p. 118-22. Incluso los abanderados del Feminismo, que propugnan la autonomía en materia de decisiones relativas a la procreación, entre ellos Rowland, aplauden la intervención estatal a fin de proteger los intereses de las mujeres en tanto grupo. (WIKLER, Norma: Society's Response to the New Reproductive Technologies: The Feminist Perspectives, 59, South Col. L.R., 1986). 
taría desconocer la responsabilidad y función tuitiva del Estado, en materias tales como la paternidad, patria potestad y explotación de la parte débil en la relación (19).

\section{b) Alcances de la reglamentación}

Ahora bien, la misión del legislador no se agota promulgando una norma técnicamente perfecta, declarando su rechazo a ciertos actos repugnantes y deplorables o pontificando acerca de la naturaleza humana, sino que debe velar por la aplicabilidad del principio enunciado, por la eficacia y vigencia social de la norma, por su cercanía con la realidad. De nada sirve una ley que, aunque vigente, no sea acatada ni aplicada; poco útil resulta un Código de Etica Profesional, si la "coima" está a la orden del día. Por algo se dice que el Derecho además de coerción es la expresión de los valores socio-culturales que imperan en una nación. Las costumbres pueden tornar en inoperante, e incluso obsoleto, un dispositivo legal. A su vez, una norma rígida o idealista, pese a sus bondades, puede imponer en muchos el costo de la clandestinidad.

En este sentido, el informe preparado por la comisión inglesa presidida por Mary Warnock (de ahí que se le conozca como el "Informe Warnock"), luego de estudiar la problemática de la inseminación artificial por donación (IAD), concluye que la práctica de IAD va a continuar creciendo con o sin sanción legal y su utilización clandestina podría ser sumamente perjudicial $(20)$.

Debemos, pues, proceder con cautela. La prudencia en temas como el que nos ocupa es aconsejable y obligatoria, ya que la reglamentación que se adopte cumplirá un rol directriz en el desarrollo de esta rama de la ciencia y la conducta de los

(19) HOLLINGER, Joan Heifetz. From Coitus to Commerce: Legal and Social Consequences of Noncoital Reproduction, 18. U. Michigan J. Law Reform, 1985, p. 896.

(20) Warnock Report, punto 4.16. 
ciudadanos; pero, además, porque debemos proceder inspirados con la razón mas que por emoción. Entre los dos extremos, un sistema prohibitivo en que excepcionalmente se autoriza el uso de estas técnicas y un sistema liberal que las prohibe en casos excepcionales, la gama de alternativas a disposición del legislador es muy rica.

A fin de no apresurar un juicio que peque de prematuro, trataremos de imaginar una sociedad que permite el uso casi irrestricto de estos adelantos científicos para poder, ante este cuadro, detectar los valores que deben motivar la regulación. En tal virtud abordaremos el tema en dos etapas. En una primera construiremos este sistema flexible y permisivo en materia de Reproducción Humana Asistida, donde en principio el Derecho franquea el acceso a todos y cada uno de sus métodos, restringiéndolos sólo en casos excepcionales. Allí evaluaremos los riesgos y problemas que estos avances tecnológicos suscitan, cómo prevenirlos y reducirlos o, en su caso, obviarlos. A la luz de este panorama liberal nos preguntaremos en la segunda parte acerca de las consecuencias o efectos que una solución así acarrearía para la humanidad, concluyendo de esta forma con una respuesta acerca de la posibilidad o prohibición de los adelantos en materia de procreación asistida. Aboquémonos, pues, a edificar este mundo de fantasía...

\section{c) Riesgos, problemas y posibles soluciones}

Por más liberal, permisivo y flexible que sea un ordenamiento legal, los riesgos que amenazan la integridad física o moral del individuo hacen imperiosa la intervención estatal. Las nuevas tecnologías imponen graves riesgos a todas las partes involucradas, esto es: a la criatura, a los donantes y a la pareja infértil.

\section{Para la criatura}

Lo primero que se ha alegado es que estos adelantos científicos afectan sustancialmente la salud de la criatura, en 
particular la FIV y TE. Datos recolectados durante la Cuarta Conferencia Mundial sobre FIV en Melbourne, Australia, en noviembre de 1985 , demuestran que hasta esa fecha habian nacido tres mil niños gracias a estas técnicas, sin más problemas que los resultantes del embarazo natural (21). Un legislador extremadamente cauto podría, en estos casos, limitar el tiempo en que un embrión pueda estar fuera del vientre materno.

Tambiên se ha alegado el daño moral o psíquico que pudiera sufrir el niño al enterarse cómo fue procreado. El mismo problema se presenta con la adopción. Los especialistas aconsejan en todos estos casos se informe al niño desde temprana edad acerca de su origen. El legislador podría hacer suya esta recomendación.

Otro problema es el relativo a la filiación, particularmente en los casos en que quien piensa fungir de padre o de madre no proporciona el material genético sino que éste es de un tercero (ej. caso típico el donante anónimo a un banco de esperma, o la donante que no sólo cede su vientre sino que provee el óvulo). Más aún, ¿cuál será la situación del menor frente a sus padres homosexuales? En este contexto toda la serie de presunciones legales con que tradicionalmente el Derecho tutela el bienestar del menor, resultan inoperantes. A manera de ejemplo, basta pensar en el caso de la mujer casada que decide fungir de "madre sustituta": la criatura si bien genéticamente no es hijo de su marido, sino de un tercero (ya que fue inseminada artificialmente), en virtud de la presunción pater is legalmente resulta siendo hijo del marido (art. 361 del Código Civil peruano de 1984). Es más, la mujer no puede demostrar lo contrario (art. 362). La dificultad no se acaba aquí sino que también involucra a la mujer. Supongamos que ella sólo alquiló su vientre, es decir, que le implantaron un embrión ya concebido sólo para que lo geste durante los nueve meses del embarazo. Cuando da a luz, ¿a quién se reputa madre de la criatura? El legislador tradicionalmente ha tenido en mente a la mujer que alumbra, ¿y ahora?

(21) ANDREWS, Lori B. The Legal Status of the Embryo, 32 Loyola L. Rev., 1986, p. 365. 
Es importante tener presente que la filiación impone deberes y responsabilidades frente al menor. El vínculo paterno/ materno-filial, que sancionó la ley, además de proteger al menor tiene por objeto proteger a la sociedad, ievitando así el incesto! Esta dimensión de las relaciones familiares es de vital importancia. Vayamos por partes.

Tomando en cuenta el bienestar del menor, lo más adecuado sería reconocer a los "padres sociales" (o sea, a quienes "encargan el bebé") como padres legítimos, pues son ellos quienes estuvieron interesados en traer esa criatura al mundo, para incorporarla a su familia. En tal virtud, el/la donante no tendría vinculación legal alguna con el menor. Esta es la solución que recogen la mayoría de los informes y proyectos legislativos del mundo (22). Con esto por lo pronto se garantiza un hogar para el menor.

El legislador también tendrá que tomar las previsiones del caso tratándose de personas solteras y homosexuales. Un sistema liberal les reconocería también a ellos "el derecho" a formar una familia. Así como un soltero puede recurrir a la adopción (art. 378 del Código Civil), el Derecho debería franquearle el acceso a la Reproducción Asistida.

Sin embargo, queda el otro tema en el tintero: ¿cómo proteger a la sociedad en general frente a la eventualidad del incesto? Dicho en otros términos, ¿quién debe aparecer en el Registro como progenitor de la criatura? Una solución podría ser obligar a que en el certificado de nacimiento aparezca quien "encargó" al bebé como padre y que el/la donante aparezca como progenitor(a) (23). Esta disposición - como veremos más adelante-contraviene el interés del donante por mantenerse en el anonimato.

(22) ROWLAND, The Social and Psychological Consequences of Secrecy in Artificial Insemination by Donor (AID) Programmes, manuscrito no publicado, 1986.

(23) ROWLAND, op.cit., alerta para que no se falsee el certificado de nacimiento en el sentido de inscribir al "padre social" como progenitor de la criatura. 
Otro medio para reducir el riesgo del incesto sería limitar el número de veces que un/una donante puede intervenir en estos casos, es decir, que sólo haya un determinado número de niños engendrados con gametos del/de la donante. Distintos proyectos legislativos limitan esta cantidad a diez . El legislador deberá tomar estas precauciones.

Antes de pasar al siguiente punto, es conveniente mencionar que pese a las ventajas de las soluciones propuestas, éstas sólo procuran cierta claridad y certeza en las relaciones de parentesco, pero que están lejos de proveer la solución perfecta. De adoptarse esta salida el legislador tendría que crear todo un nuevo sistema de presunciones y pruebas tendientes a acreditar la filiación (por ejemplo, la prueba de los grupos sanguíneos carecería de eficacia).

Asimismo, cabe destacar que los derechos hereditarios del menor se refieren a sus "padres sociales", mas no al donante.

Otro de los riesgos que la ciencia aún no puede evitar es el del nacimiento de los niños lisiados o deformes. Incluso para los matrimonios más estables una criatura así es causa de sufrimiento, costo y preocupación. Lo más posible es que quien "encargara" el bebé no quiera recibirlo por ser una "carga". Cierto que si la criatura lleva los genes del padre social, el rechazo podría verse aminorado, pero no queda descartado. El legislador debe tomar las precauciones del caso, ya sea imponiéndole a los padres sociales la responsabilidad de esta criatura, asumiendo él mismo esta tarea (sería algo así como un "orfelinato para lisiados"), o flexibilizando las reglas sobre el aborto, solución ésta que algunas naciones están prontas a sancionar.

También debería tomarse precauciones para aquellos casos en que surjan desavenencias en la pareja que "encargó" el bebé, fallezca uno de los padres o sea declarado interdicto.

Por último, y no por ello menos traumático, queda el problema de la manipulación y experimentacion con embriones. Este tema nos lleva a todo el campo relacionado con la "ingenie- 
ría genética", que hoy en día permitiría a Hitler culminar su sueño de la raza perfecta. Escapa a los alcances de este estudio profundizar en este fenómeno apasionante desde el punto de vista científico, pero espeluznante a la luz de la Etica, Moral y Derecho. Sólo mencionaremos algunas de las posibilidades que se presentan: determinar el sexo, color de ojos, nivel intelectual (IQ), contextura, estatura y raza del embrión, amén de toda la gama de posibles combinaciones entre gametos humanos y animales, gestación de embriones humanos en el útero de un animal, granjas de órganos con material embriónico (conocidos como "organ farms"), en que se podría producir hígados, tejidos cerebrales y riñones para curar casos de cáncer de hígado, enfermos de parkinson o a quienes perdieron un riñón. El legislador, aunque permitiendo el uso casi irrestricto de las nuevas técnicas de Reproducción Humana Asistida, debería proscribir la Ingeniería genética.

En términos generales, vemos pues cómo el legislador podría tomar las previsiones del caso para asegurar la situación del menor. Analicemos, ahora, la situación del/ la donante.

\section{Para el/la donante}

En el caso de los donantes también se presenta el riesgo de daño fisico o moral, no tanto en el varón como en la mujer que tiene que ser sometida a la intervención quirúrgica y/o al embarazo (24). El legislador debería imponer la contratación de un seguro de enfermedad y de vida en favor de la donante, así como atención médica antes, durante y después del alumbramiento. El daño moral que el renunciar a la criatura que uno ha gestado trae consigo, puede ser traumático. De allí que la mujer que desee fungir como madre sustituta deba ser asesorada y avisada sobre estos traumas y consecuencias. En caso de gestar y proveer además el material genético (vg. óvulo), podría reco-

(24) Todo embarazo trae consigo graves trastornos físicos y psíquicos para la mujer, además del riesgo de perder o dañar alguno de sus órganos reproductivos. 
nocérsele el derecho a ser informada acerca de la salud y bienestar de la criatura.

El proceso de selección de donantes acarrea, asimismo, diversas dificultades. ¿Quiénes son elegibles? ¿Qué criterios usar para la elección? ¿Cómo garantizar que el gameto no padezca ningún mal? Uno de los mecanismos que tiene el legislador a su alcance es el de sancionar la obligatoriedad de determinados exámenes y test médicos que le permitan al especialista detectar cualquier anormalidad genética, física o fisiológica en el donante, así como llevar a cabo los exámenes necesarios para determinar las características del esperma donado. Queda a discreción del legislador decidir a quién le atribuye la facultad de vincular al donante con la persona interesada en su donación.

Una de las preocupaciones más graves, especialmente tratándose de cesión de vientres, es el referido a la comercialización y explotación del donante, que está a merced de los grupos económicos de poder, particularmente si pertenece a uno de los sectores marginales de la población. Para evitar esto el legislador deberá prohibir la intermediación de empresas con fines de lucro (v.gr. S.A., S.C.R. Ltda.).

Además, tal como ocurre para el matrimonio, deberá establecerse una edad mínima para ser donante. En igual sentido deberían establecerse programas educativos para informar a los distintos sectores de la población acerca de las ventajas y desventajas de estas técnicas y de intervenir como donantes.

Estrechamente vinculado con el tema de la explotación está aquél relativo a la remuneración del donante, o si se quiere a la manera cómo se reclutan donantes. ¿Su participación debe ser gratuita o a título oneroso? En última instancia lo que se está decidiendo es la naturaleza de los "servicios" que presta el donante. Algunos, basándose en la inalienabilidad de los órganos y material humano, propugnarán la gratuidad de esta operación; otros le asignarán al donante el derecho a los costos incurridos; $y$, por último, otros considerarán justo se pague un precio por el beneficio procurado. Es de imaginar que si el 
"servicio" es a título gratuito, pocos, particularmente pocas mujeres serían voluntarias como donantes. Por otro lado, el pago de una remuneración podría inducir a muchos a ocultar ciertos datos acerca de su estado físico y pasado clínico. Parecería que la solución intermedia (pagar sólo los costos incurridos) podría ser muy favorable (25).

A fin de evitar cualquier tipo de explotación o aprovechamiento por una parte en desmedro de la otra, el legislador podría proponer contratos modelo o exigir la aprobación administrativa o judicial del mismo. Los colegios profesionales quedarían encargados de esta autorización, así como de la reglamentación necesaria.

En este punto, es conveniente reflexionar acerca de los especialistas que asisten a las partes con auxilio de la nueva tecnología. La complejidad de algunos de estos procesos (no tanto la inseminación artificial, pero sí en los demás) y los riesgos que ellos acarrean ameritan la intervención de personal calificado. Hace poco en los Estados Unidos un grupo de médicos, especialistas en endocrinología reproductiva e infertilidad, llamó la atención sobre este punto (26). En su opinión, para poder ejercer en esta área de la medicina debía exigirse un entrenamiento supervisado, así como la obtención de un título y certificado de especialización.

Otro de los puntos que tiene que evaluar el legislador es el de la anonimidad y confidencialidad acerca de la identidad deV de la donante. Ellos, por temor a verse envueltos en juicios de filiación o resultar responsables por la salud y educación del

(25) Los franceses tienen un sistema especial para obtener semen en los casos de IAD: Los interesados en recibir este servicio deben persuadir a algunos amigos para que hagan una donación al banco de esperma. De esta forma se distribuye en la sociedad el riesgo de tener pocos donantes, enfatizando asimismo el carácter gratuito de la operación. (Warnock Report, punto 4.27).

(26) BLACKWELL, Richard y otros. Are We Exploiting the Infertile Couple?, 48 Fertility and Sterility, 1987, p. 735. 
menor, abogan por quedar en el anonimato. Sin embargo, como hemos visto hace un momento al ocuparnos de los riesgos que afectan al menor, el legislador debe cuidar las relaciones de parentesco a fin de evitar, en lo posible, el incesto. Ante este evidente conflicto de intereses, el legislador puede optar por: a) revelar el nombre del/de la donante en la partida de nacimiento, garantizándole que esa inscripción no acarreará ningún tipo de derechos y obligaciones para con el menor (situación análoga a la del padre del hijo dado en adopción); o b) mantener absoluta reserva acerca de la identidad del/de la donante, limitando al máximo las veces que pueden fungir como donantes. En este último caso el riesgo se habría minimizado, pero no obviado. Además, en esta línea, debería tomarse las precauciones necesarias para que el niño en su mayoría de edad pueda tener acceso a la información relativa a las características genéticas e historial clínico de su progenitor/a.

Con las previsiones expuestas a groso modo, los intereses $\mathrm{del} /$ de la donante estarian salvaguardados. Nos queda por estudiar la situación de la persona o de la pareja que tendrá a su cargo la crianza del bebé.

\section{Los padres}

"No es padre quien engendra, sino quien cria": con estas palabras la cultura popular ha sabido valorar a quien tiene a su cargo a un niño desde pequeño hasta su mayoría de edad. La persona, la pareja que, por infertilidad u otra causa, no quiere 0 no puede engendrar, gestar, y alumbrar un bebé, pero desea poder criarlo y tenerlo a su cargo, es el "padre social o la madre social" (en contraposición a la madre genética y/o gestacional). El/ella es quien "encarga" el niño que será concebido y/o gestado mediante algunas de las técnicas de Reproducción Humana Asistida.

Como en los demás casos, aquí también tenemos que ocuparnos de la salud fisica y mental de los interesados. Si alguno de los padres sociales contribuye además con el material genético o participa en la gestación de la criatura, los riesgos y 
problemas a que está expuesto son idénticos a aquéllos inherentes a la "procreación natural", en virtud de la cual todos hemos sido engendrados. La integridad psíquica, en cambio, puede verse sustancialmente alterada si las expectativas son demasiado grandes y no se ven colmadas. Esto último puede deberse a que los padres estaban mal informados acerca de las tecnologías y sus posibilidades de éxito. En uno u otro caso el legislador debería cuidar porque se divulge la información exacta, indicando las posibilidades reales de éxito así como los riesgos que estas técnicas traen consigo (vgr. posibilidades de un niño lisiado). Los padres, además, deberían recibir asesoramiento psicológico que los prepare para cualquier eventualidad.

Los padres también están expuestos a la explotación por parte de quienes intermedian y asisten en estos casos de procreación. Para ello, como ya se ha sostenido, debe prohibirse la participación de personas jurídicas con fines de lucro en estas operaciones. Asimismo, debería tratar de disminuirse el costo de estos procedimientos mediante la cobertura del seguro.

Por último, para garantizar el normal desenvolvimiento de esta práctica, ante la eventualidad de un incumplimiento por parte del donante (vgr. de la mujer que cede su vientre), debería otorgarse la custodia de la criatura a los padres sociales, tal como acordaron las partes en un principio. De esta manera se aminorarían los riesgos de que pudiesen verse frustradas las expectativas e integridad psíquica de los padres, permitiéndose el uso generalizado y pacífico de estas técnicas.

\section{La función del Derecho ante el avance tecnológico}

En este "mundo de fantasía" que hemos descrito, en que la ciencia provee los medios necesarios para aliviar el "sufrimiento" de todo aquél que, por una u otra causa, no está en aptitud de procrear pero desea formar una familia; en esta sociedad, en que el Estado sólo interviene para evitar la explotación del débil, proteger al menor o salvaguardar la integridad físico-mental de las partes, ¿qué habría cambiado? ¿Qué valores hubiesen resultado afectados? ¿Qué hubiésemos ganado? En última instancia, ¿queremos una sociedad así? ¿Estamos dispuestos a pagar el precio que ella impone? 
El Dr. Allan Leal, Vicepresidente de la Comisión de Reforma Legislativa de Ontario, hizo constar su discordia respecto de la admisibilidad de algunas técnicas de reproducción asistida, enfatizando que todos los adelantos de la ciencia no acarrean su propio imperativo categórico. Muchos de los avances de la medicina son aplaudidos porque promueven el mejoramiento de la condición humana, sostiene. Aceptamos otros bajo ciertos controles que aseguren este resultado. Y otros, concluye, tendrán que ser descartados, por lo menos temporalmente, hasta que acomodemos nuestra concepción de lo que es una sociedad aceptable, justa y realista (27).

\section{a) Desmitificación y soberbia científica}

Una de las críticas centrales que se esgrimen contra las nuevas técnicas de Reproducción Asistida, es su total desprecio por la vida humana. iSe ha reducido la procreación a un mero proceso tecnológico! Rasgándose las vestiduras, se objeta la "cosificación" del embrión; no es más que un producto con un precio determinado, se alega (28). Se ha llegado a decir que el embrión constituye una nueva forma de propiedad, un bien de consumo que puede ser producido a satisfacción del comitente y vendido en el mercado donde los futuros padres son los consumidores de servicios altamente especializados (29). El profesor Kass habla de la despersonalización de la procreación. Invocando un cambio de actitud, afirma que estamos viendo deteriorarse la imagen del ser humano como algo espléndido y divino. El

(27) Allan Leal's Dissent en Ontario Report.

(28) El Vaticano, a través de la Congregación para la Doctrina de la Fe, ha publicado recientemente la Instrucción sobre el Respeto por la Vida Humana en sus orígenes y sobre la dignidad de la procreación (1987), en que proscribe toda intervención en el proceso natural de la procreación (en adelante "Instrucción sobre Bioética"). Asímismo, enfatiza la "cosificación" a que se somete el embrión.

(29) OVERALL, Christine. Pluck a Fetus from its Womb: A Critique of Current Attitudes Toward the Embryo/Fetus, 24 U. Western Ontario L.R., 1986, p. 7. 
precio que tendremos que pagar, agrega, por bebés perfectos es transferir la procreación del hogar al laboratorio y su consiguiente transformación en mercancía. Nos estamos deshumanizando, concluye (30).

El hecho de que los médicos desempeñen un rol activo en la procreación, develando todo el misterio que la cubría, pone en tela de juicio la presencia invisible de un Ser Supremo, cuestiona la omnipotencia del Creador. Ahora, sostiene Overall, podemos decidir, si queremos procrear, cuándo, qué y qué cantidad de niños queremos traer al mundo - una responsabilidad cuasideífica (31). ¿Qué nos está pasando? Parecería que le hemos perdido todo el respeto a la naturaleza. Ahora que nos podemos procrear artificialmente ya no la veneramos ni consideramos como antes. Ha cambiado nuestra relación hacia ella. Los adelantos científicos han desmitificado el proceso natural de la reproducción humana. Eso que creíamos intrínsicamente "natural", innato al ser humano, constante a lo largo de la historia y ajeno a toda intervención tecnológica, ya no lo es. Ya no se requiere el encuentro físico del varón y la mujer; es más, las nuevas técnicas pueden suplir su ausencia.

El proceso desmitificador es irreversible, la ciencia ya nos reveló el secreto. Por más que se prohiban todas y cada una de las modalidades de la Reproducción Asistida, el origen de la vida ha sido desmitificado. Estamos ahora en un proceso de cambio y adaptación, en que somos conscientes de estos adelantos pero no los llegamos a aprehender totalmente. Nos causa estupor, nos afecta la sola idea de pensar en la intromisión de la ciencia en aquello que considerábamos sacro. Somos testigos del cambio y aunque quisiésemos desconocerlo y nos cueste adaptarnos, tenemos que convivir con esta nueva realidad. La necesidad de vivir en función de determinadas creencias es

(30) KASS, Leon. The New Biology: What Price Relieving Man's Estate?, 174 Science, 1971, p. 784 y s.

(31) OVERALL, Christine. Pluck a Fetus from Its Womb: A Critique of Current Attitudes Toward the Embryo/Fetus, 24 U. Western Ontario L.R., 1986, p. 6 y s. 
inherente al ser humano. Nuestra propia naturaleza es temporal y efimera. Indefectiblemente vamos a morir. La muerte es una realidad común a todos los hombres; para salvarnos de ella tenemos que creer en un ser o fuerza suprema que en caso de una tragedia nos pueda salvar, ya sea de manera práctica o por lo menos que nos sirva de consuelo. En este afán de alcanzar lo absoluto, de atrapar lo inatrapable, el hombre crea mitos (v.gr. el mito de la eterna juventud, el mito del origen de la civilización). Mediante ellos tratamos de dar una explicación que nos consuele y ayude a entender eso que parece inalcanzable.

El mito no es más que una metáfora, cuyo contenido y explicación varía a lo largo de la historia. Tan pronto cambia nuestra relación para con esa realidad que creiamos sagrada, el mito deja de ser tal, se desmitifica. Pero, a su vez, al desmitificar una realidad mistificamos otra. El proceso de desmitificación supone también la mitificación del elemento que nos sirvió para conseguir lo primero. Así, por ejemplo, los indios pielrojas bailaban de cierta forma para atraer la lluvia. Ellos creían que su baile causaba la lluvia. La ciencia nos enseña que es la naturaleza quien determina la lluvia. Al desmitificar el baile de los pielrojas estamos, a nuestra vez, mitificando la ciencia, a través de la cual entendimos la lluvia.

En igual sentido se desmitificó la ley de la gravedad cuando el hombre pudo volar. Antes de ese momento la idea del "hombre volador" resultaba inverosímil. Ahora nos parece evidente e indispensable. Tanto antes como ahora la ley de la gravedad existe y despliega su total eficacia; lo que ha cambiado es nuestra relación para con ella: la ley de la gravedad no es invencible; podemos vencerla en ciertas circunstancias y con ciertas limitaciones.

Cada mito se explica dentro de un contexto temporal aplicado a un grupo determinado (a los ojos de quien cree en él, el mito cumple una función dentro del sistema y es perfectamente racional). Cada vez que cambia la relación de las personas respecto del elemento mitificado, el sistema sufre un reajuste. Todo cambio causa conflicto. Somos seres de costumbres y nos cuesta adaptarnos. Nos aterra la posibilidad de un cambio 
porque termina con el sistema que teníamos pre-establecido. Pero, lo que hoy es bueno, ayer era malo; sin ir muy lejos, basta imaginar los trastornos que causó Galileo al sostener que la tierra no era el centro del Universo, o Jesucristo al propugnar la igualdad de los hombres, o la Revolución Francesa al guillotinar a Luis XVI acabando así con la monarquía.

Durante el cambio las emociones se enardecen, el sistema amenaza con desmoronarse y el fin de los tiempos parece estar cerca. Pero luego, cuando nos familiarizamos con el cambio, después de rescatar los valores que parecian esenciales y reconstruir nuestra "Weltanschauung", los ánimos vuelven a su estado normal y la barca del progreso zarpa nuevamente hacia mares aún no navegados. Cuando las aguas se calman, las emociones pasan al olvido. Hoy, por ejemplo, al estudiar la Historia, esos acontecimientos que en su momento encendieron los sentimientos más controvertidos son simples datos que el alumno debe aprender. Sabemos lo que ocurrió, pero no lo sentimos.

La década de los 80 nos ha llevado a la cima del cambio. Los adelantos de la ciencia en materia de procreación asistida nos han dejado a todos estupefactos. En estos momentos nos parece que los avances científicos van a transtornar nuestras vidas, porque estamos viviendo el cambio. La nueva tecnología nos toca íntimamente en lo más profundo de nuestras convicciones y valores. Presenciamos la desmoronación de todo un sistema, nos sentimos personalmente atacados, somos partes del cambio, con el agravante que los medios de comunicación imponen. Lo que antaño hubiera terminado en una reforma, hoy adquiere dimensiones revolucionarias por la difusión y participación de los medios de comunicación. El reto y la responsabilidad del legislador y de quienes contribuyen con su pluma al desarrollo y adecuación de las instituciones sociales, es doble: la complejidad del fenómeno que nos ocupa y la premura porque el Derecho cumpla una función catalizadora.

Debemos enfatizar que lo expuesto no afecta ni modifica la responsabilidad de los científicos y de la sociedad en su conjunto por tratar de poseer lo inalcanzable. Al desmitificar la procrea- 
ción humana, al alterar el curso "natural" de los acontecimientos, nos revelamos contra el orden prestablecido, tratamos de controlar la naturaleza e imponer nuestras propias reglas. Nuestra ansia de poder es insaciable. ¿A dónde queremos llegar? ¿Cuál es el limite? En honor a la verdad, no es la ciencia quien impone el curso de su evolución; es más bien la sociedad la que determina el destino de la ciencia (32). Sembramos demasiadas expectativas en los avances científicos y nos autoconvencemos de necesidades inexistentes. Ya no nos contentamos con personajes como "Superman" - ni qué decir de un Ser Supremo-; nuestra ambición es ser nosotros mismos los "héroes de la película", olvidar nuestras limitaciones y desconocer nuestra condición humana. Pero, por más que queramos, ino somos seres divinos!

Desde nuestros orígenes hemos tenido estos sueños de grandeza. Adán y Eva comen del fruto del Arbol del Bien y del Mal porque querían igualar a Dios, y precisamente al hacerlo ratifican su condición humana, sus limitaciones y ambiciones. En la mitología griega, Prometeo personifica nuestra soberbia; robó el fuego del Olimpo para entregárselo a los mortales. Zeus lo hizo castigar por creerse superior a los dioses. Los bancos de esperma nos permiten eternizarnos; la reproducción in vitro y el alquiler de vientres por conveniencia establecen una relación de dominación sobre nuestro origen y destino, evidenciando una vez más nuestra soberbia y vanidad. Pero, precisamente, al tratar de hacernos divinos nos hacemos más humanos, porque queremos ser dioses cuando en realidad no lo somos. Quizás debemos ser conscientes de nuestro destino y preguntarnos qué somos en realidad: ¿inferiores a los ángeles o superiores a los simios?

(32) Así también OAKLY, Anne: Fertility Control - A Woman's Issue, $4 \mathrm{~J}$. Obstetrics \& Gynaecology (Supp. 1), 1984, p. 5 y ss. WIKLER, Norma Juliet: Society;s Response to the New Reproductive Technologias: The Feminist Perspectives, 59 Southern Cal. L.R., 1986, p. 1043 y ss. 
Retomemos el punto de partida. ¿Qué otros cambios trae esta cajita de Pandora bautizada con el nombre de Reproducción Asistida? Sus detractores destacan la comercialización de la vida, el hecho de que el embrión puede ser producido y "vendido" en el mercado, la deshumanización de la procreación y despersonalización de la vida. Pero, ¿hemos llegado a estos extremos? Y si así fuera, ¿queremos pagar su precio?

Respecto del embrión se pueden decir muchas cosas, pero algo es cierto: que no es un mero conglomerado de átomos o material biológico. Si bien no tenemos rituales especiales para lamentar la pérdida de la mujer que aborta, ni consideramos la muerte de un embrión como la de cualquier persona (33), sí valoramos el feto humano más que a un animal o que una cosa cualquiera. Aun cuando alguien descubriese un manjar especial, nos repugnaria la sola idea de comer embriones humanos. Un embrión de pocos días no tiene forma humana; sin embargo, en su origen es humano y potencialmente - si todas las circunstancias le son favorables- terminará siendo una persona humana (34). De ahí que merezcan respeto y consideración. Desde el momento de la concepción nace un nuevo ser humano con material genético propio, perfectamente individualizado, cuyo metabolismo respira y responde a los cambios de su medio ambiente. El óvulo una vez fecundado adquiere vida propia, distinta y diferente a los gametos que la originaron. El embrión es humanamente "algo"; posee el poder de convertirse en una persona como nosotros (35).

En esta línea de pensamiento, la FIV no sólo es inmoral sino

(33) KASS, Leon. Making Babies Revisited, 54 Public Interest, 1979, p. 38.

(34) KASS, op.cit., p. 39 y s.

(35) Esta es la posición que defiende Kass a lo largo de sus distintas publicaciones, asimismo la Iglesia Católica se adscribe a esta tesis enfatizando que la dignidad de la vida humana empieza con la concepción. 
que debería prohibirse, ya que supone la destrucción de los embriones concebidos que no se implantan en el útero femenino. Por otro lado, se alega, si la vida humana comienza con la concepción, debe ser protegida desde ese momento. Además, se agrega, el embrión cumple una función simbólica. Su destrucción por causas económicas o de conveniencia puede afectar nuestra conducta respecto de los demás seres humanos. La deliberada aniquilación de embriones, en tanto símbolos de vida, puede llevarnos a que tratemos lo simbolizado de la misma forma con que tratamos al símbolo (36).

Pero, ¿estamos con vencidos de querer llevar este planteamiento hasta sus últimas consecuencias? Reflexionemos. Respeto al embrión, sí, pero ¿tanto como a un niño? ¿Podemos equiparar un óvulo fertilizado con un adulto? ¿Merece un embrión la tutela y protección propia de toda persona? Parecería que ésa no ha sido la intención declarada por el legislador. El art. 1 del Código Civil de 1984, dispone que "la persona es sujeto de derecho desde su nacimiento. La vida humana comienza con la concepción. El concebido es sujeto de derecho para todo cuanto le favorece. La atribución de derechos patrimoniales está condicionado a que nazca vivo". De la lectura de este dispositivo podemos colegir que: a) el concebido tiene vida humana, pero no es persona; b) sólo para lo que lo favorezca se le imputará como sujeto de derecho. Nuestro ordenamiento legal parece, pues, proponer una solución diferente a la expuesta en los párrafos anteriores. Tratar de leer algo distinto de esta norma sería violentar su espíritu. ¿Es que el legislador ha querido realmente marcar una diferencia entre el "concebido" y el "nacido"? ¿Por qué habría querido el codificador del '84 distinguir entre persona humana y vida humana? ¿No será que el problema central no gira en torno a definiciones filosóficas acerca del comienzo y naturaleza de la vida, en tanto tal, sino que más bien es una opción jurídica, parafraseada en términos de preguntarse: ¿desde qué momento tiene la vida significado jurídico? ¿En qué momento ocurre algo que el Derecho decide

(36) Así KASS, op.cit., p. 43. David Ozar citando ROBERTSON, John. Ethical and Legal Issues in Cyropreservation of Human Embryos, 47 Fertility and Sterility, 1987, p. 371 y ss. Nota. nr. 15. 
proteger? Parece un juego de palabras pero en ella se esconde un sentido revolucionario.

Las palabras del británico Harris (37) plasman con sencillez el meollo del problema. En efecto, él sostiene lo siguiente:

Los gametos son portadores de vida mucho antes de la concepción. El óvulo femenino y el semen del varón, son ambos células vivas, células humanas. El óvulo, por ejemplo, sufre un proceso de crecimiento y maduración. La vida es un proceso continuo e ininterrumpido que se desarrolla de generación en generación. No es, pues, la vida la que comienza con la concepción (38). Pero si no es así, se pregunta Harris, ¿no será que un nuevo individuo nace con la fertilización, que un ser potencialmente humano comienza a existir? El mismo se responde: varias "cosas" pueden comenzar con la concepción. Esta puede dar lugar a un quiste, a un tumor, a dos individuos, o a un futuro ser.

Refiriéndose a la idea del ser humano en potencia, Harris afirma que el hecho que algo pueda volverse " $\mathrm{X}$ " (incluso de manera inevitable, cosa que no ocurre necesariamente con el óvulo fecundado), no es razón suficiente para tratarlo como si fuese " $\mathrm{X}$ ". Todos vamos inevitablemente a morir un día, pero ello no es razón suficiente para que tratemos a otras personas como si estuviesen muertas. Por otro lado, agrega, no es cierto que el óvulo fertilizado sea potencialmente un ser humano. El óvulo virgen y el semen son potencialmente tan humanos como el embrión. Sostener que el óvulo fertilizado es un ser humano en potencia, no es otra cosa que decir que si ciertos hechos ocurren (como su implantación) y otros no (como un aborto espontáneo) se convertiría eventualmente en un ser humano.

(37) HARRIS, John. In Vitro Fertilization: The Ethical Issues, 33 Philosophical Quarterly, 1983, p. 222 y s.

(38) El biólogo Clifford GROBSTEIN en su detenido estudio The Early Development of Human Embryos 10, J. Med. \& Phil., 1985, p. 234 y s. concluye que la concepción da origen a una nueva generación desde el punto de vista genético pero no al comienzo de la vida. 
Precisamente lo mismo se puede decir del óvulo y del semen (39). Si ciertos hechos le ocurren al óvulo (vgr. encontrarse con el semen) y ciertos hechos le pasan al semen (vgr. encontrarse con el óvulo) y otras cosas no ocurren (vgr. tropezarse con un anticonceptivo), eventualmente se convertirán en un nuevo ser humano. Todo lo que puede decirse acerca del óvulo fertilizado es que el tejido humano vifo o la vida en sí no comienzan con la concepción, tampoco la vida humana; ambas continúan.. No necesitamos determinar cuándo comienza la vida sino desde cuándo importa moralmente y por qué. Dicho en otras palabras, ¿desde qué momento tiene la vida un significado moral? (40) ¿Qué trato merecen los embriones? ¿Cómo debe proteger el Derecho al óvulo fecundado? Algunas veces el saber frasear la pregunta aclara el paso para arribar a una respuesta.

Nuestro legislador no ha querido equiparar el embrión con un niño ni con un adulto casado (41). Tampoco el feto viable tiene rango de persona - a menos que nazca vivo-. El embrión sólo es una vida en potencia que el Estado protege en la medida que estime conveniente (42). La personería, y con ella la imputación

Este punto también aparece en KUHSE, Helge y SINGER, Peter. The Moral Status of the Embryo: Two Viewpoints, en Test-Tube Babies, eds. William Walters y Peter Singer, Oxford University Press. Melbourne, 1984. p. 57 y ss.

(40) Mary Warnock, Catedrática de Oxford y Presidente de la Comisión Británica, comentando el artículo de Harris, comparte su planteamiento. WARNOCK, Mary, In Vitro Fertilization: The Ethical Issue, 33, Philosophical Quarterly, 1983. p. 238.

(41) Así también ANDREWS, op.cit., p. 561. CAHILL, Lisa Sowle. In Vitro Fertilizacion: Ethical Issues in Judaes-Christian Perspective, 32 Loyola L.R., 1986. p. 348 y ss.

(42) Burt VAN DE WEGHE, en su análisis de la jurisprudencia norteamericana titulado Waller, Warnock and Roe v. Wade: Variations on the Status of the Orphan Embryo, 2 J. Contemporary Health, Law \& Policy, 1986. p. 242, demuestra que la Corte Suprema norteamericana no le ha reconocido al feto viable la protección garantizada por la Constitución a las personas. 
de derechos y obligaciones, responde a un criterio netamente formal. Aquél a quien se le pone la "máscara" (43) es persona a la luz del Derecho. El legislador no desconoce la naturaleza especial del óvulo fertilizado, ni de los gametos por separado; sólo establece un orden de prelación, una escala de graduación que comienza con los gametos y termina con el que ha nacido. No es que uno sea más humano que el otro ni cosa por el estilo. Ambos son humanos, ambos "viven". Lo que ocurre es que uno ha ingresado a la comunidad jurídica con absoluto e irrestricto goce de derechos y obligaciones, mientras que el otro está "en vías de".

A lo largo de la historia la fecha cierta del nacimiento ha marcado un hito en cuanto a goce de derechos se refiere, así como la certeza de la mayoria de edad acarrea el beneficio de otros derechos. En igual sentido, desde la concepción hasta la muerte, pasando por el nacimiento y la mayoría de edad, el Derecho gradúa el tipo y los alcances de la protección que proporciona. El concepto de la "viabilidad"no es más que otro hito en esta escala de tutela a la vida humana. Antes de ese momento, nadie discute la existencia de "vida humana"; lo distintivo es que se vuelve imperativa desde ese instante (44).

La persona humana sigue siendo el fin supremo de la sociedad y del Estado, como lo preceptúa nuestra Constitución en su

(43) Por algo el vocablo griego "personare" significa disfrazarse, hablar a través de una máscara, hacerse persona.

(44) Incluso aquellos ordenamientos que consagran el derecho de aborto lo restringen considerablemente luego del momento de viabilidad del feto. A su turno, Santo Tomás de Aquino, en la línea aristotélica, habla de un plazo de formación del feto ( 40 días si fuese varón y 90 si es mujer) antes del cual la terminación del embarazo no era considerada aborto (CAHILL, op.cit., p. 352). Andrews concluye que el embrión no es ni una persona ni una cosa, su tratamiento legal depende del tipo de Derecho que se alegue: una será la solución en caso de Derecho Sucesorio, otra en materia de Responsabilidad Extracontractual y otra en Derecho Penal (ANDREWS, Lori, The Legal Status of the Em. bryo, 32 Loyola L.R., 1986. p. 367). 
primer dispositivo. Los adelantos de la ciencia no han desvalorizado la persona ni han mellado su humanidad. Cada ser humano merece respeto y protección, todo lo que de él se derive recibirá una cuota de tutela legal, pero él es el único acreedor a la totalidad.

\section{c) Sexualidad y procreacion: ¿ ina unidad?}

Otro fenómeno que ha sorprendido al mundo entero es la posibilidad de engendrar una criatura sin necesidad de coito sexual. Con este paso la ciencia culmina la evolución iniciada con los anticonceptivos, en el sentido de separar la sexualidad de la procreación. El debate que suscitó la "píldora" cobra vigencia, reclutando entre sus filas, ya no sólo a los seguidores de San Pedro, sino a grupos feministas y público en general. El divorcio entre la sexualidad y la procreación se extiende más allá de la participación familiar y tratamiento de la infertilidad, desplegando cuestiones de singular envergadura.

¿Qué sentido tiene separar la procreación humana de la sexualidad?, se pregunta el médico-filósofo Kass (45). Ser varón o mujer, prosigue, sólo tiene sentido en relación al otro y, con ello, en la posibilidad de procrear a través de esa unión. La procreación es, a juicio de este autor, la actividad humana por excelencia, pues nos involucra tanto corporal y espiritual como racionalmente. A su turno, la Iglesia Católica enseña que la sexualidad y la procreación están íntimamente ligadas al compromiso matrimonial. En esta línea, la procreación es fruto de la entrega mutua de los cónyuges dentro del matrimonio (46).

Pero, ¿qué es "natural"? ¿Nuestra percepción de lo que es la "procreación" no está, acaso, determinada por convicciones morales, religiosas y culturales? Ante los avances de la ciencia,

(45) KASS, Leon. The Meaning of Life in the Laboratory, 1-2 Bioethics Reporter, 1985, p. 235 y s.

(46) Así enseña el Vaticano en la Instrucción sobre Bioética (1987). 
¿podemos seguir hablando de una única forma de procreación humana?

\section{Del control de la natalidad a la planificación familiar}

La realidad en que vivimos ha sufrido un cambio dramático en las últimas décadas. La familia tradicional, estable y armoniosa, ha dejado de ser la regla, viéndose amenazada por la escalada de divorcios, aumento de hijos concebidos fuera del matrimonio, profesionalización de la mujer y desarrollo de la sociedad de consumo. En la medida que la mujer ingresa a la vida profesional, pospone el matrimonio y la crianza de los hijos, la necesidad de planificar el número y oportunidad de cada embarazo adquiere una importancia singular (47).

Del control de la natalidad motivado por el interés estatal de limitar el aumento poblacional, hemos pasado a la planificación familiar. Más que el Estado, son los ciudadanos en general, la pareja en particular, y la mujer en especial, los interesados en poder adecuar la procreación a su ritmo de vida y planes futuros.

Como hemos explicado, la equiparación de la mujer en los distintos campos de la actividad humana -desafortunadamente aún más a nivel teórico que real- ha modificado los esquemas tradicionales de la procreación y de la familia.

Desde antaño, relata la feminista Wikler (48), la mujer ha tenido la posibilidad de inseminarse artificialmente. Los medios estaban allí, pero por siglos nunca se le ocurrió utilizarlos. A juicio de la citada estudiosa, el meollo del asunto para entender el sentido de las nuevas tecnologías radica en comprender por qué las antiguas no las usaron y por qué quienes estaban en

(47) Así también ROBERTSON, John, Procreative Liberty and the Control of Conception, Pregnancy and Childbirth, 69 Virginia L. Rev., 1983, p. 406.

(48) WINKLER, op.cit., (Society's Resp. ...), p. 1043 y ss. 
aptitud de usarlas no las tomaron en cuenta. Este análisis, agrega, demuestra que la pista central no nos lleva del laboratorio al cambio social, sino en sentido inverso. El auge de esta nueva rama de la ciencia, concluye, responde a los cambios en la relación varón-mujer, moralidad-sexualidad, y el nuevo rol y status de la mujer, así como al creciente número de parejas infértiles que desean formar una familia.

\section{La familia: un valor}

Pese a todos estos cambios la familia sigue siendo, como diría Chestertone, "una célula de resistencia contra la opresión". La familia es la unidad mínima, esa micro-sociedad donde el hombre se siente acompañado, protegido, valorado por lo que es y no por lo que sabe o tiene (49). La familia vincula a sus miembros con el pasado dándoles, además, un sentido de continuidad hacia el futuro. Sin la familia, afirma Kass, no tendríamos incentivos para interesarnos por lo que ocurra después de nuestra muerte. Al eliminar esta comunidad, estaríamos a merced de un presente solitario e impersonal (50). La familia tiene una estructura esencialmente personal, en que cada uno ocupa un lugar privilegiado.

Si bien los matrimonios estables han dejado de ser la regla, en occidente la familia sigue siendo un valor. Para muchos, el término engloba la pareja y los hijos, para otros se limita a la pareja, otros hablan de familias homosexuales y otros de la "gran familia". El término familia hace referencia a una realidad socio-cultural que tiene un significado ético y dimensiones morales. Podemos discrepar acerca del sentido que le atribuimos pero, como tal, la familia es un valor. Así lo ha entendido el Constituyente de 1979 al declarar en el Preámbulo de la Constitución Política del Estado, que "la familia es la célula básica de

(49) KASS, Leon, The New Biology: What Price Relieving Man's Estate, 174 Science, 1971, p. 784 y s.

(50) Asi S.S. Juan Pablo II en Be not Afraid de Andre FROSSARD, Image Books, Nueva York, 1985, p. 111 y s. 
la sociedad y raiz de su grandeza, así como ámbito natural de la educación y cultura". En nuestra sociedad la familia cumple, aún hoy, un rol estelar.

Ahora bien, ¿qué entendemos por "familia"? En términos generales, podría decirse que es la célula básica que está conformada por los padres y los hijos; los abuelos, tíos, primos y sobrinos constituyen la familia en un sentido más amplio. En nuestro medio, pues, se descarta toda unión homosexual.

Si bien tradicionalmente la familia giraba en torno al matrimonio, distinguiéndose entre hijos legítimos e ilegítimos, actualmente se ha liberalizado la institución. Los cambios a que hemos hecho referencia en relación al rol de la mujer, desarrollo de la sociedad de consumo y adelantos tecnológicos, han influido en la regulación familiar. El legislador no sólo ha equiparado a todos los hijos (art. 235 y 2116 C.C.), sino que además reconoce la igualdad del varón y la mujer en los quehaceres del hogar (art. 234, 290 y 292 del C.C.) y faculta (no le impone) a la mujer para llevar el apellido del marido (art. 293 y art. 24 C.C.).

El Derecho promueve y aplaude la regularización de los "matrimonios irregulares"; éstos, sin embargo, también caen bajo la protección de la familia. La unión del varón y la mujer que voluntariamente hacen vida en común merece tutela legal. La comunidad familiar se yergue así como pieza clave en la gestación, crianza y formación de las futuras generaciones. Es en este sentido que la Iglesia Católica santifica el matrimonio. La estabilidad de la sociedad requiere que los niños nazcan en el seno familiar (51).

Pues bien, precisamente porque queremos proteger la familia necesitamos aliviar el problema de las parejas infértiles $\mathrm{y}$ de quienes temen transmitir algunas malformaciones genéticas. La ciencia no nos ha creado necesidades artificiales; es

(51) Y que la familia se base en el matrimonio, enseña la última Instrucción de la Sagrada Congregación para la Doctrina de la Fe sobre Bioética (1987). 
nuestra sociedad quien motiva los avances tecnológicos. Los científicos simplemente se han limitado a recoger nuestro clamor. Incluso quienes reprueban las bondades de estos adelantos admiten que a "estas alturas" hay un consenso en nuestra sociedad; que las parejas infértiles deben tener acceso a la fertilización in vitro (52).

La planificación familiar es una faceta más en el quehacer diario de las amas de casa. Ella debe estar, también, en la agenda del legislador. La gama de alternativas que brinda la ciencia moderna es muy amplia: desde la esterilización hasta la legalización del aborto, pasando por los anticonceptivos y las nuevas modalidades de procreación asistida.

Mientras que la esterilización anula por completo las facultades reproductivas de la persona y el aborto termina con la vida del embrión, los anticonceptivos y las técnicas de reproducción asistida se limitan a separar temporalmente la sexualidad de la procreación. La píldora marcó el primer hito en la historia de esta evolución al permitir el coito sexual sin procreación. Luego la fertilización in vitro cierra el círculo haciendo posible la concepción sin sexualidad. La "reproducción en el laboratorio", como se suele denominar, es querida, elegida, intencionada y controlada - características todas ellas que distinguen al homo sapiens de los demás animales. Esto ha llevado a decir que la reproducción asistida es, incluso, más racional y humana que la llamada procreación natural, porque es producto de una elección y no de una mera coincidencia (53).

\section{La procreación como derecho de dos personas}

A este cambio debemos agregarle la creciente demanda

(52) CAHILL, Lisa Sowle, In Vitro Fertilization! Ethical Issues in JudaeoChristian Perspective, 32 Loyola L.R., 1986, p. 356 (traducción libre).

(53) Asi, OVERALL, Christine, Pluck a Fetus from its Womb: A critique of Current Attitudes toward the Embryo/Fetus, 24 U. Western Ontario L.R., 1986, p. 6. 
por tener descendencia de "la misma sangre". Como sostienen Robertson (54) y Hollinger (55), la sociedad moderna no considera la adopción como una solución deseable. Actualmente, el mayor anhelo del individuo no se circunscribe a la crianza de la prole (que de ser así podría ser adoptada), sino a transmitir sus genes, entablar vínculos sanguíneos y compartir el mismo material genético con la generación futura. Este deseo no es innato ni está determinado biológicamente, afirma Hollinger, sino que obedece a necesidades culturales.

Pero ¿qué significa "tener un hijo propio"?, pregunta Kass. En tanto "lo mío" no es lo propio de uno sino de dos, el deseo de tener un hijo que sea de uno es el deseo de la pareja de engendrar mediante la unión conyugal una criatura que es producto de dos personas hechas una. La procreación, concluye, es por definición un acto de dos (56).

\section{El "derecho" de los solteros}

¿Podría entonces una mujer soltera reclamar el auxilio de la ciencia para engendrar un hijo? ¿Debe el Derecho extender el uso de las nuevas técnicas a los solteros? ¿El hecho de que se necesiten gametos masculinos y femeninos debe verse reflejado en la reglamentación que se adopte? En última instancia, ¿hasta qué punto puede el ordenamiento jurídico permitir la deliberada concepción de un ser que tendrá un solo padre? Los bancos de esperma existen (57) y los solteros pueden recurrir a la adopción. ¿Por qué no habría de franqueárseles el acceso a los adelantos de la medicina? Sin afán de desconocer la "validez" de

(54) ROBERTSON, op.cit., p. 423.

(55) HOLLINGER, Joan Heifetz, From Coitus to Commerce: Legal and Social Consequences of Noncoital Reproduction, 18 J. Law Reform, 1985 , p. 870 y ss.

(56) KASS, Leon, Making Babies Revisited 54 Public Interest, 1979, p. 44.

(57) En los EE.UU. distintos grupos feministas han constituido bancos de 
estas demandas, creemos que confunden algunos términos. Una cosa es la adopción y otra la Procreación Asistida. En la adopción se busca proteger a una persona ya nacida, darle la oportunidad de tener un padre, educarse, desarrollarse e integrarse a la sociedad. Es por el bien del menor que el Estado en determinada circunstancia permite la participación de un soltero en la adopción. La situación es diametralmente opuesta en el caso de las nuevas técnicas procreativas. Aquí se engendra una nueva vida humana para satisfacer las necesidades de quien solicita este "servicio".

Los distintos ordenamientos y comisiones que han abordado el tema excluyen a los solteros como beneficiarios de la nueva tecnología (58). Robertson, que se ha ocupado en extenso de estos temas, enseña que las personas solteras tienen el derecho a no ser esterilizadas, el de poder usar anticonceptivos, concebir, gestar, dar a luz, así como a criar y educar a sus hijos, pero no tienen el "derecho a procrear", porque la procreación cae bajo la protección legal del matrimonio (59). El Estado no persigue a las madres solteras; por el contrario, debe brindarles protección y asistencia médica. Ello, empero, no significa que deba incluir a los solteros como beneficiarios de las nuevas tecnologías. Para tal propósito los solteros tienen abierta la vía de la adopción.

esperma en Vermont (1975), Los Angeles (1979) y Oakland (ver COREA, Gene, The Machine Mother: Reproductive Technologies from Artificial Insemination to Artificial Wombs, Harper \& Row, Perennial Library ed., Nueva York, 1986, p. 44 y s.). Las estadísticas revelan que hasta 1978 alrededor de $6 \mathrm{mil} \mathrm{a} 20 \mathrm{mil}$ niños habían nacido por IAD (HOLLINGER, op.cit., p. 870).

(58) Ast, por ejemplo, en los EE.UU. el Uniform Parentage Act de 1973, Oregon Revised Statute de 1977, restringe el uso de IAD a personas casadas. La American Fertility Society en sus New Guidelines for the Use of Semen Donor Insemination de 1986 (46 Fertility \& Sterility, Supplement 2, 1986, pp. 955-1035), sólo se refiere al uso de IAD por una pareja. El Warnock-Report opina en igual sentido.

(59) ROBERTSON, John, Procreative Liberty and the Control of Conception, Pregnancy and Childbirth, 69 Virginia L. Rev., 1983, p. 432 y s., asf como p. 419 nota nr. 36. 
Cualquiera podría cuestionar nuestra posición alegando que no hay ninguna diferencia entre el hecho que una persona soltera tenga relaciones extramatrimoniales o que recurra a un banco de esperma. Es más, en la primera hipótesis la mujer se estaría prostituyendo con el fin de salir encinta, mientras que en el segundo mantendría incólume su dignidad. En este orden de ideas, se concluye, la situación del menor sería exactamente la misma. En efecto, en ambos casos estaríamos ante la figura de una madre soltera con un hijo "sin padre", situación ésta que no encaja dentro del ideal familiar que el Derecho quisiera garantizar. Sin embargo, hay una diferencia sustantiva. Mientras en el primer caso el legislador está con los brazos atados, no pudiendo hacer nada al respecto (quizás, invocar a las partes por el bienestar del menor o declarar la legitimidad de la familia), teniendo que ver cómo se erosiona y desestabiliza la unidad familiar, en el segundo supuesto el legislador puede encausar con carácter imperativo la conducta de los particulares. Amén de proscribir estas prácticas, puede imponerles sanciones disciplinarias - hasta criminales-a los profesionales y a todo aquél que intervenga, asista o promueva el uso por los solteros de cualquiera de las técnicas de procreación asistida. El personal especializado por llevar a cabo la inseminación in vitro, los encargados de los bancos de esperma y los médicos en general serían los responsables de hacer cumplir los objetivos trazados por el legislador.

\section{5. $\dot{\imath}$ Un "derecho a procrear"?}

Descartados los solteros y excluidos los homosexuales, nos queda por analizar el caso de los casados y de las uniones de hecho. ¿Pueden ellos acceder a estos adelantos tecnológicos? ¿Tienen, acaso, un derecho a procrear? De ser así, ¿abarca este derecho las técnicas de procreación asistida?

Como es sabido, uno de los derechos fundamentales de la persona es el de la privacidad. Todo individuo es autónomo. La Constitución le reconoce el derecho al libre desenvolvimiento de su personalidad (art. 2, inc. primero) y el derecho a la intimidad personal y familiar (art 2, inc. quinto). La persona es libre de 
decidir cuándo, cómo y con quién desea procrear. En un campo tan íntimo y personal como es la procreación, el Estado no debe, en principio, ejercer ningún tipo de ingerencia a no ser por razones que amenacen la salud de los propios individuos o el bienestar general.

La libertad del individuo en materia de procreación y sexualidad está íntimamente ligada al matrimonio. En la medida que la procreación escapa al ámbito netamente personal para engendrar a un nuevo sujeto de derecho distinto e independiente de quienes lo procrearon, la acción individual adquiere una nueva dimensión, que el Estado debe tutelar. La Constitución consagra la importancia de la familia como célula básica de la sociedad. El Derecho no sólo protege a la familia sino que garantiza su continuidad. En tal virtud, el art. 289 C.C. sanciona el débito sexual de los cónyuges, así como la obligación de fidelidad y asistencia que se deben recíprocamente (art. 288 C.C.). Los casados tienen, pues, el derecho de hacer vida en común, de cohabitar y como fruto de tal relación traer un nuevo ser al mundo.

El punto materia de estudio es si este derecho se extiende, también, a la procreación asistida (60). Dos conceptos entretejen el discurso: el débito sexual y la procreación. Tradicionalmente uno condicionaba el otro, pero ahora que la ciencia los ha podido divorciar debemos esclarecer cuáles son sus alcances. Ingresamos a terrenos inexplorados. Las ideas que arriesgaremos sólo son los primeros pasos reconociendo el terreno en un campo aún no explorado.

Imaginemos el caso de una pareja en que uno de los cónyuges es estéril. Con ayuda de la ciencia esta pareja podría ver realizado el sueño de su vida: tener una familia. Pongámonos en el supuesto más extremo aún en que ambos cónyuges, perfectamente sanos y fértiles en potencia, son incapaces de procrear en su unión mutua. ¿Debe esta dificultad física ser obstáculo a que la pareja cumpla el mandato "creced y multipli-

(60) Así también ROBERTSON, op. cit., p. 427. 
caos", considerando que con auxilio de la medicina podrían ver sus sueños hechos realidad? Con Robertson (61) estimamos que las limitaciones físicas sólo deben impedir participar en la concepción, gestación y alumbramiento en la medida que la ciencia o la sociedad no pueda superar esas limitaciones. Cosa distinta ocurre con limitaciones psíquicas o mentales, porque en esos casos el individuo no puede ser consecuente con la responsabilidad que sus actos le imponen. Si la inteligencia humana provee los medios para aliviar y liberar a los esposos de sus limitaciones reproductivas sin causar ningún daño a otros bienes jurídicamente tutelados, creemos que el Derecho no debe ser obstáculo sino, más bien, debe facilitar el camino.

Alguien podria alegar que en esta línea de argumentación los únicos beneficiarios de las técnicas de procreación asistida deben ser los esposos y, más en concreto, parejas infértiles. Quisiéramos compartir este raciocinio, pero al hacerlo nos topamos con dificultades prácticas. La infertilidad, como se sabe, no es tanto una condición objetiva, una enfermedad, sino una situación basada en condiciones sociales y también económicas. El profesor Robertson (62) explica de manera muy ilustrativa esto. Supongamos, dice, el caso de un varón cuyo esperma es capaz de fertilizar un óvulo. ¿Si es impotente o su esperma es de baja densidad, debe considerarse infértil, no obstante que con la ayuda de la inseminación artificial y concentración de esperma podría culminarse la fecundación? ¿Es la mujer, cuyas trompas de falopio están bloqueadas, infértil, pese a que una operación quirúrgica ayudaría a evitar la obstrucción? ¿Es una mujer que está a punto de sufrir una pérdida, estéril si se niega a hospitalizarse por cinco meses para poder salvar su embarazo? ¿Es infértil quien no desea tener relaciones heterosexuales? Además de la dificultad de definir la fertilidad, concluye, hay que considerar lo que implicaría tener que demostrar, en ciertos casos, la infertilidad de la pareja. El proceso sería sumamente "intrusivo" y de difícil físcalización. Además, resulta poco pro-

(61) ROBERTSON, op.cit., p. 411y 429.

(62) ROBERTSON, op.cit., p. 430, nota nr. 67. 
bable que una pareja fértil quiera recurrir a estas técnicas. También hay que tener presente que, además de las parejas infértiles, todo aquel que padezca de un defecto congénito hereditario podría acceder a la procreación asistida.

La idea de limitar el acceso a las parejas casadas resulta pertinente. En efecto, a lo largo de esta exposición hemos demostrado la importancia de la familia en nuestra cultura y la protección que ella merece. Nadie duda que lo ideal sería partir de una relación matrimonial estable, reconocida y legitimada por la autoridad civil, y en su caso, religiosa; que los hijos se críen y desarrollen en el seno de la unión familiar; y que la familia gire en torno al matrimonio. La crisis por la que atraviesa la sociedad ha afectado a la familia, haciendo que este panorama familiar sea difícil de emular. Pues bien, si este cuadro ideal sigue teniendo vigencia, si las bondades de una unión estable y legitimada apelan aún hoy a nuestros más nobles ideales, el legislador no sólo puede, sino que debe recoger estas inquietudes y, plasmándolas en disposiciones imperativas, debe limitar el acceso a las técnicas de procreación asistida a las parejas casadas.

\section{Los acreedores de estos adelantos}

Entonces, sólo las personas casadas (fértiles e infértiles) podrán beneficiarse de los adelantos de la ciencia. Ni los solteros, ni las parejas homosexuales gozarían de este privilegio. ¿Esto quiere decir que un matrimonio podría procrear de manera natural, por medio de una de las modalidades de inseminación artificial (IAH o IAD), fertilización in vitro (FIN), transferencia de embriones (TE), cesión de vientres, y en todo caso, siempre tendría abierto el camino de la adopción? No vayamos tan de prisa. La AIH no ofrece mayores dificultades; la propia Iglesia reconoce la bondad del procedimiento (63). Los casos de AID son más delicados pues involucran a una tercera persona en la relación: el donante. Sin embargo, creemos que cuidando a

(63) Vaticano Instrucción sobre Bioética (1987). 
la sociedad de los riesgos que acarrea el incesto, podría admitirse esa técnica. En ese sentido se inclinan la mayoría de informes y proyectos legislativos de la materia.

La FIV presenta una variante distinta. A fin de evitar la inútil destrucción de embriones no implantados debería invocarse al cuerpo médico y científico, para que perfeccionen el procedimiento. Mientras tanto, sólo debería permitirse un uso restringido. $\mathrm{La} \mathrm{TE}$, a diferencia del "alquiler de vientre", no ofrece mayores dificultades. Los convenios de "cesión de vientres" son más controvertidos. Si bien los casos en que una mujer por motivos altruistas interviene para gestar el bebé de otra resultan conmovedores, la comercialización y explotación a que estarian expuestas la mayoría de madres sustitutas deja mucho que desear. Si bien creemos que la experiencia del embarazo no debe ser desvinculada de los demás aspectos procreativos -iy menos aún por mera conveniencia!- el Derecho debería permitir actos de entrega personal, como el de la hermana que se ofrece a gestar el hijo de su hermana, o la madre que hace lo propio respecto de su hija. Fuera de estos casos, el legislador, en caso decida legitimar la cesión de vientres, debería sancionar los mecanismos necesarios para evitar la sumisión de la madre sustituta.

Por último, en todas las hipótesis analizadas el legislador debería tomar en consideración las precauciones sugeridas en este trabajo, así como responsabilizar al cuerpo médico por el debido cumplimiento de estos objetivos. Sin perjuicio de lo expuesto, debería constituirse una comisión encargada de estudiar el adelanto e impacto de las nuevas tecnologías en nuestro medio, para poder así, al cabo de un plazo prudencial, evaluar el rumbo trazado $y$, si fuera el caso, darle a nuestra nave el destino acertado. 